\title{
Impact of Parasitic Resistances on the Output Power of a Parallel Vertical Junction Silicon Solar Cell
}

\author{
Nfally Dieme, Moustapha Sane \\ Laboratory of Semiconductors and Solar Energy, Department of Physics, Faculty of Science and Technology, \\ Cheikh Anta Diop University, Dakar, Senegal \\ Email: nfallydieme@yahoo.fr
}

Received 16 November 2015; accepted 13 March 2016; published 16 March 2016

Copyright (C) 2016 by authors and Scientific Research Publishing Inc.

This work is licensed under the Creative Commons Attribution International License (CC BY). http://creativecommons.org/licenses/by/4.0/

(c) (i) 0pen Access

\begin{abstract}
This paper describes the theoretical model for calculating IV-curve of parallel vertical silicon solar cells (SCs) based on solving diffusion-recombination equation for such SC, which was suggested that two IV curve zones (those which are close to the short current and open circuit points) can be linearized. This linearalization allows obtaining the values of shunt $\left(R_{s h}\right)$ and series $\left(R_{s}\right)$ resistances. The evolution of the electric power based on these resistances was illustrated to show the values that shunt and series resistances must have to obtain a good efficiency.
\end{abstract}

\section{Keywords}

Series Resistance, Shunt Resistance, Power, Vertical Junction

\section{Introduction}

The depletion of fossil energy sources and the heavy pollution of the atmosphere push the researchers to find an alternative such as solar energy obtained by using solar panels. The strong demand for solar power requires a deep research to increase the efficiency of solar panels. It is therefore urgent for us to find anything that may weaken the smooth functioning of the panels. The performance of these panels can be known and improved by the study of certain electrical parameters such as parasitic resistances. These parameters are derived from the junction non-ideality, volume carriers recombination, current leakages, and, on the other hand, the material resistivity, metallic contacts and collection grids [1] [2]. The aim of this work is two-fold: to show an analytical approach of the measurement of parasitic resistances and their impact on the performance of the solar cell. 


\section{Theoretical Background}

The parallel vertical junction silicon solar cell is presented in Figure 1 [3].

We assume that illumination is made with polychromatic light, and is considered to be uniform on the $z=0$ plane. The contribution of the emitter is neglected.

When the solar cell is illuminated, there are simultaneously three major phenomena that happen: generation, diffusion and recombination.

These phenomena are described by the diffusion-recombination equation obtained with [3] [4]:

$$
\frac{\partial^{2} n(x)}{\partial x^{2}}-\frac{n(x)}{L^{2}}=-\frac{G(z)}{D} .
$$

$D$ is the diffusion constant:

$$
D=\mu \cdot \frac{K}{q} \cdot T .
$$

With $q$ as the elementary charge, $k$ the Boltzmann constant; $T$ is the average temperature prevailing in the material.

$G(z)$ is the carrier generation rate at the depth $z$ in the base and can be written as [5] [6]:

$$
G(z)=\sum_{i=1}^{3} a_{i} \mathrm{e}^{-b i z}
$$

$a_{i}$ and $b_{i}$ are obtained from the tabulated values of AM1.5 solar illumination spectrum. $n(x), L, \tau$, and $\mu$ are respectively the density of the excess minority carriers, the diffusion length, lifetime and mobility.

The solution to the Equation (1) is:

$$
n(x)=\theta_{1} \sinh \left(\frac{x}{L}\right)+\theta_{2} \cosh \left(\frac{x}{L}\right)+\sum \frac{a_{i}}{D} L^{2} \mathrm{e}^{-b i z} .
$$

Coefficients $\theta_{1}$ and $\theta_{2}$ are determined through the following boundary conditions [7]:

- $\quad$ at the Junction $(x=0)$ :

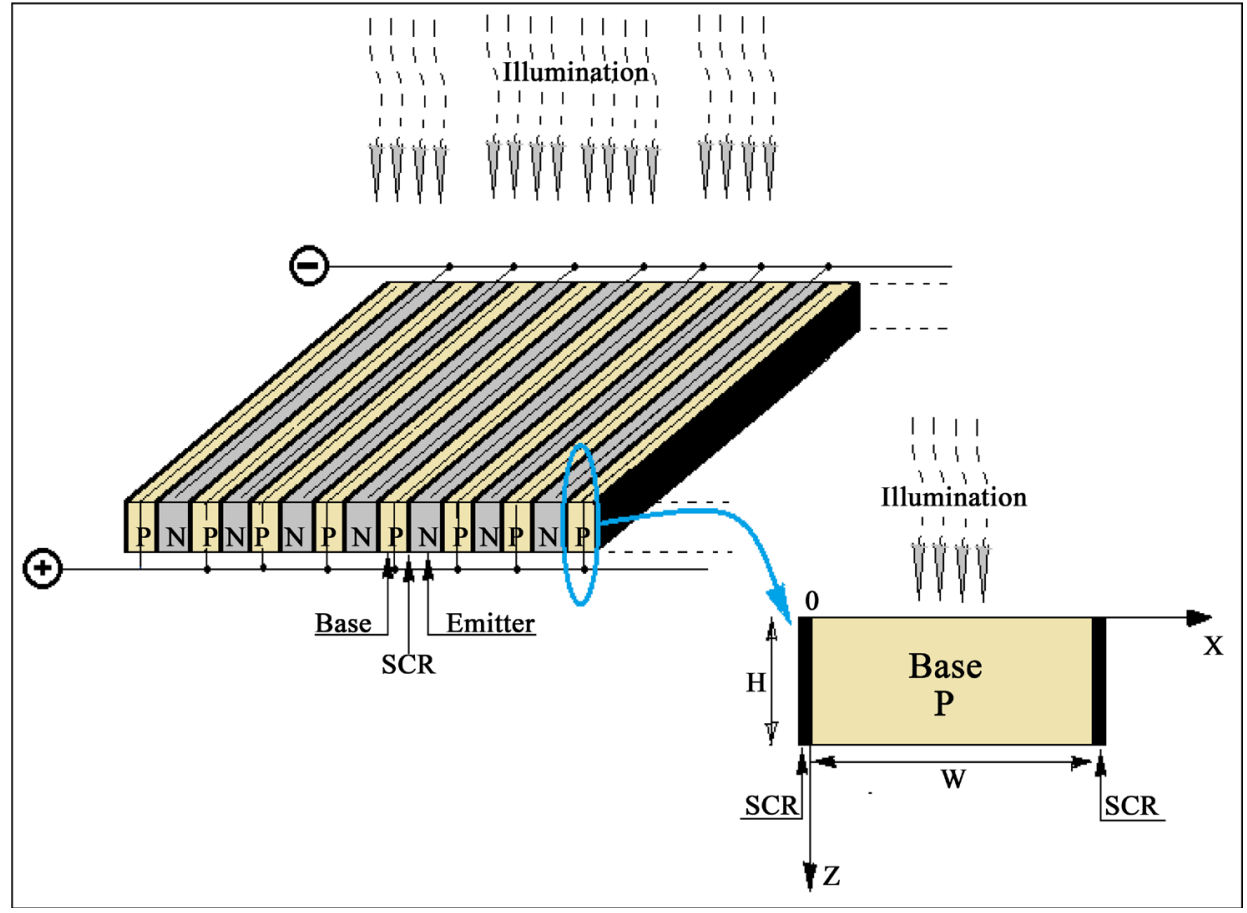

Figure 1. Vertical parallel junction solar cell $(H=0.02 \mathrm{~cm} ; W=0.03 \mathrm{~cm})$. 


$$
\left.\frac{\partial n(x)}{\partial x}\right|_{x=0}=\frac{S_{f}}{D} n(0) .
$$

This boundary condition introduces a parameter $S_{f}$ which is called recombination velocity at the junction.

- $\quad$ in the middle of the base $(x=W / 2)$ :

$$
\left.\frac{\partial n(x)}{\partial x}\right|_{x=\frac{w}{2}}=0 .
$$

The photocurrent $J_{p h}$ is obtained from the following relation [8] [9]:

$$
J_{p h}=\left.q D \frac{\partial n(x)}{\partial x}\right|_{x=0} .
$$

The photo-voltage given by [8] [9]:

$$
V_{p h}=\frac{k \cdot T}{q} \cdot \ln \left(N_{B} \cdot \frac{n(0)}{n_{i}^{2}}+1\right)
$$

with

$$
n_{i}=A_{n} \cdot T^{\frac{3}{2}} \cdot \exp \left(\frac{E g}{2 K T}\right) .
$$

$n_{i}$ refers to the intrinsic concentration of minority carriers in the base [10].

$A_{n}$ is a specific constant of the material $\left(A_{n}=3.87 \times 10^{16}\right.$ for silicon), $E g$ is the energy gap and $N_{B}$ is the base doping rate.

The current-voltage characteristic is illustrated by the Figure 2 below.

This characteristic presents two very significant zones:

Area 1 is called the short-circuit operation point vicinity. The current-voltage characteristic in this area is illustrated by Figure 3.

It can be noticed that the current-voltage characteristic at the vicinity of the short-circuit operation point is a straight line:

$$
J_{p h}=J_{s c}-\frac{1}{R_{s h}} \cdot V_{p h}
$$

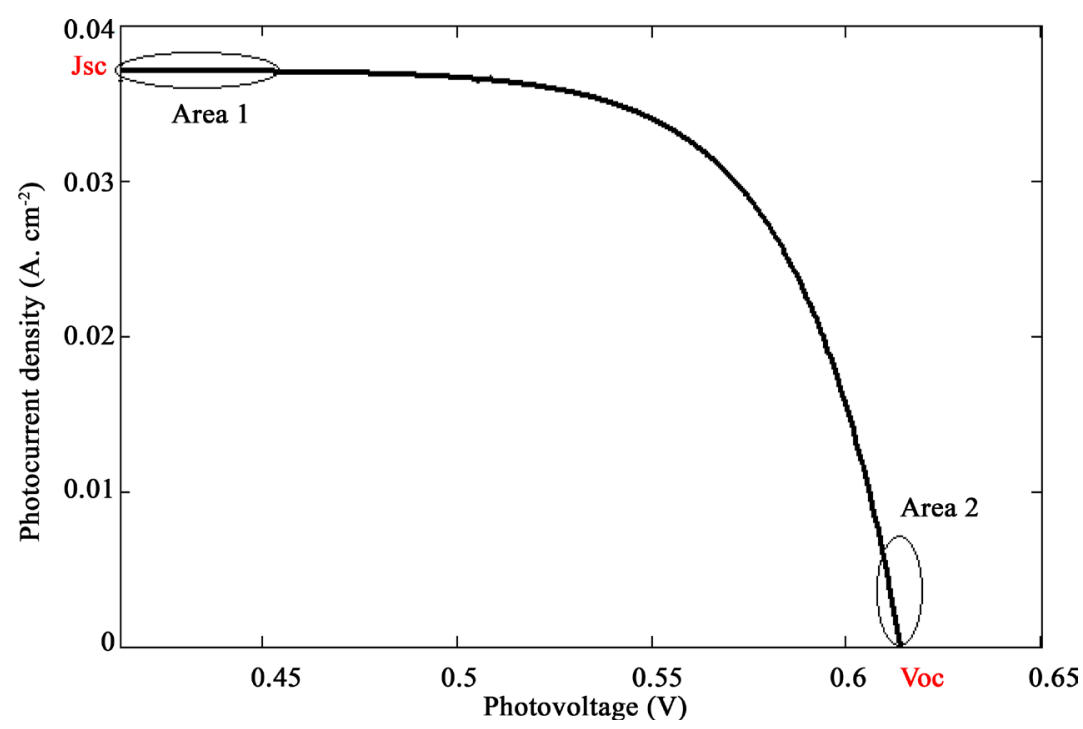

Figure 2. Current-voltage characteristic $\left(z=10^{-3} \mathrm{~cm}\right)$. 
with

$J_{s c}$ : short-circuit current density.

$R_{\text {sh }}$ is internal resistance, called shunt resistance.

From the Equation (10), the expression of $R_{s h}$ is:

$$
R_{s h}=\frac{V_{p h}}{J_{s c}-J_{p h}} .
$$

Area 2 of Figure 2 is called the open-circuit operation point vicinity. The corresponding characteristic is illustrated by Figure 4 below.

The current-voltage characteristic at the vicinity of the open-circuit operation point is a straight line:

$$
V_{p h}=V_{o c}-R_{s} \cdot J_{p h}
$$

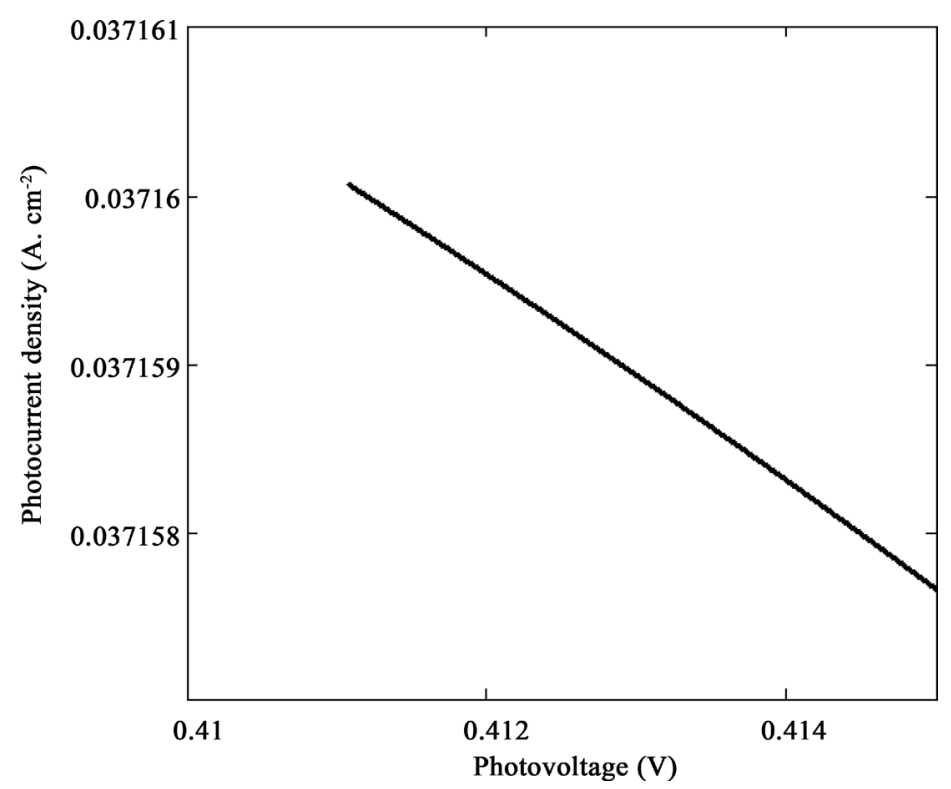

Figure 3. Current-voltage characteristic at the vicinity of the short-circuit operation point $\left(z=10^{-3} \mathrm{~cm}\right)$.

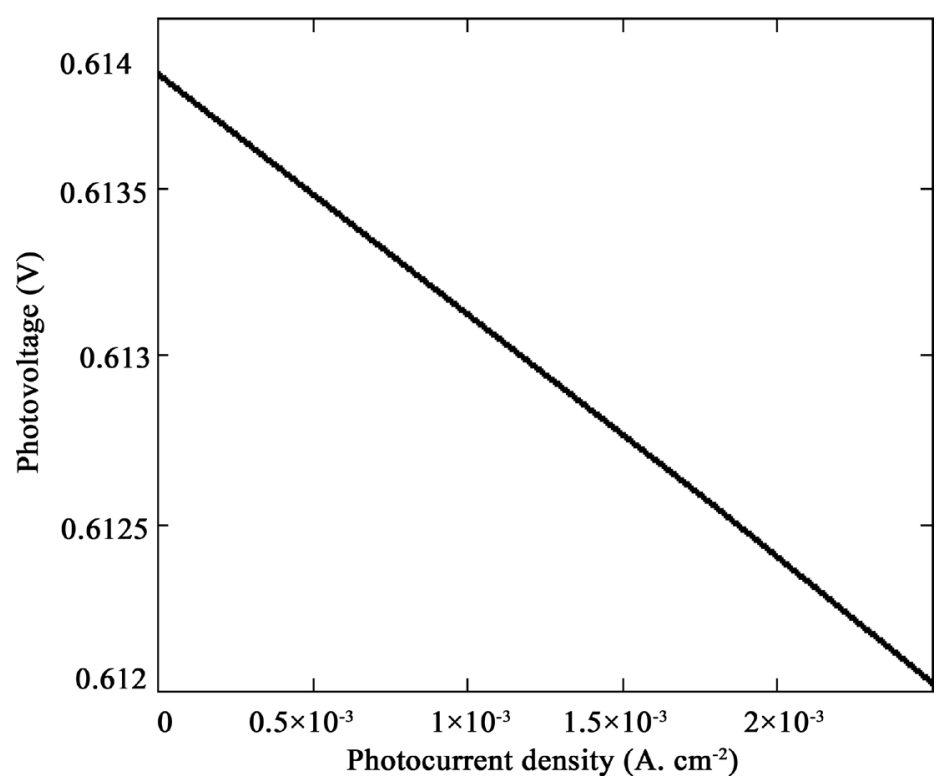

Figure 4. Current-voltage characteristic at the vicinity of the open-circuit operation point $\left(\mathrm{z}=10^{-3} \mathrm{~cm}\right)$. 
with

$R_{s}$ : is internal resistance, called series resistance.

$V_{o c}$ : open-circuit photovoltage.

From the equation (12) the expression of the series resistance is:

$$
R_{s}=\frac{V_{o c}-V_{p h}}{J_{p h}} .
$$

The effects of these resistances are noticeable when the solar cell operates in one of the follow cases: in a short-circuit situation, $R_{s}$ is negligible as compared to $R_{s h}$; and in an open-circuit situation $R_{s h}$ is negligible in return [11].

\section{Results and Discussion}

This section is concerned with the profile of electrical power regarding parasitic resistances.

Figure 5 illustrates the profile of the output power regarding the shunt resistance.

It can be noticed that power increases along with shunt resistance $\left(R_{s h}\right)$. The values taken by $R_{s h}$ are high as shows it the scientific literature [12].

Indeed shunt resistance $\left(R_{s h}\right)$ is an internal resistance that is maintained by the solar cell to be opposed to the current leakage around the junction. $R_{\text {sh }}$ also explains the volume and surface recombination of carriers. $R_{s h}$ is said to be high when several electrons cross the junction to be collected as photocurrent [12].

Thus volume and surface recombination and current leakage are all the lower as $R_{s h}$ is high. Consequently the solar cell is powerful when shunt resistance is high as the curve in Figure 5 shows.

The profile of the output power regarding the series resistance is illustrated by Figure 6 .

It can be noticed that an increase in the series resistance causes decrease in the output power. The values taken by $R_{s}$ are low. But they are in agreement with those which one finds in the scientific literature [12].

The series resistance $\left(R_{s}\right)$ comes from the resistivity of the material used, from the metallic contacts and the collection grid. It also should be added that $R_{S}$ emerges in a context of opposition to the diffusion of charge carriers to be collected as output-current at the junction. This same observation was also said in the scientific literature [2] where we learn that, when the output current increases the PN junction behaves as a resistance to oppose current.

High $R_{S}$ decreases the flow of electrons which cross the junction. Consequently the solar cell is all the more powerful as $R_{S}$ is low.

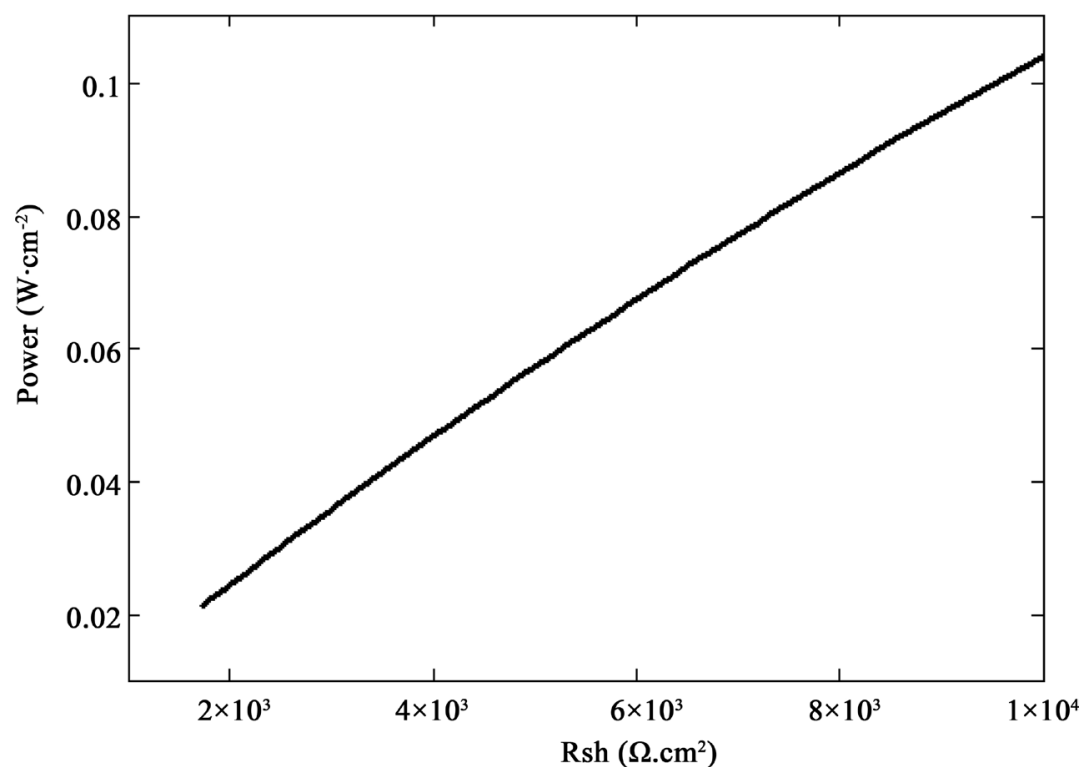

Figure 5. Electric output power versus shunt resistance $\left(z=10^{-3} \mathrm{~cm}\right)$. 


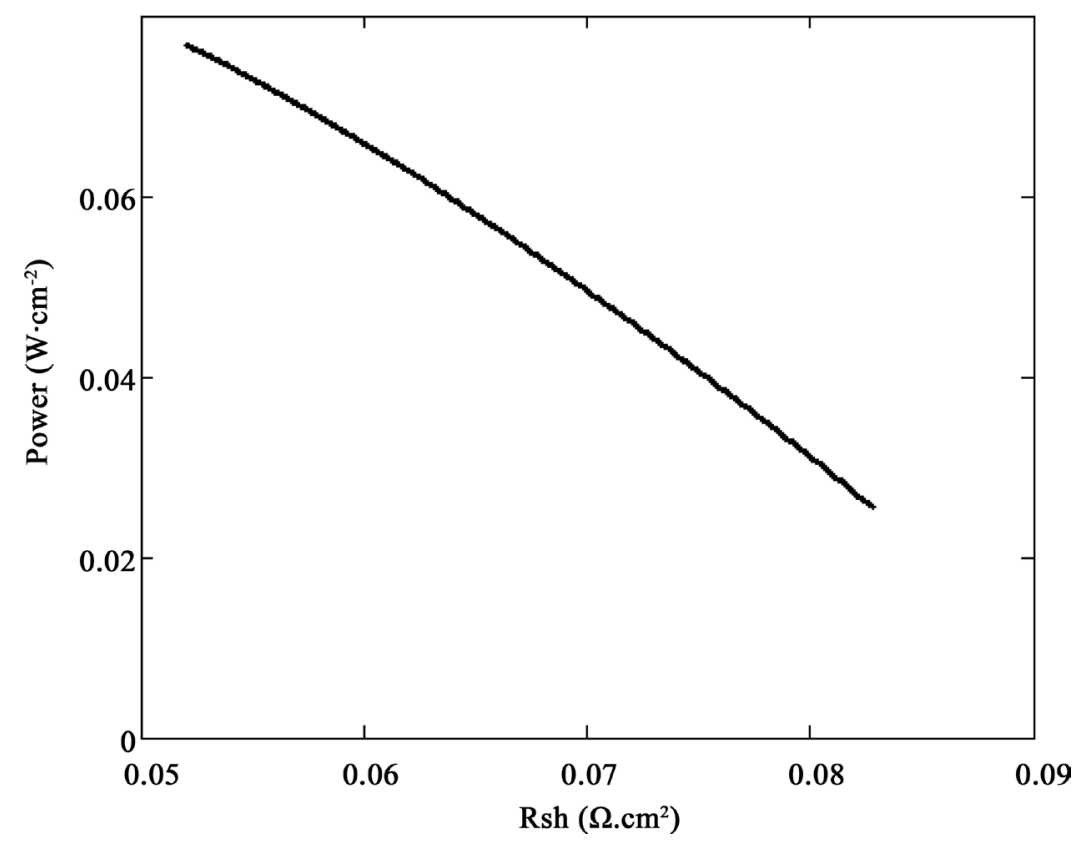

Figure 6. Electric output power versus series resistance $\left(z=10^{-3} \mathrm{~cm}\right)$.

\section{Conclusions}

Through an analytical approach, the present work has allowed a measurement of the parasitic resistances (series and shunt resistances) of a vertical junction solar cell. This approach relies on linearalization of the curve through the short-circuit and open-circuit areas. It has thus shown that a solar cell is powerful when the series resistance is low and shunt resistance is high.

This work can be deepened by making a detailed study on the impact of parasitic resistances on other electrical parameters such as photocurrent, photovoltage and the diffusion capacity of solar cells.

\section{References}

[1] Samb, M.L., Zoungrana, M., Sam, R., Dione, M.M., Deme, M.M. and Sissoko, G. (2010) Etude en modelisation à 3-d d'une photopile au silicium en régime statique placée dans un champ magnétique et sous éclairement multispectral: Détermination des paramètres électriques. Journal des Sciences, 10, 23-38.

[2] Bensalem, S. and Chegaar, M. (2013) Thermal Behavior of Parasitic Resistances of Polycrystalline Silicon Solar Cells. Revue des Energies Renouvelables, 16, 171-176.

[3] Dieme, N., Sane, M. and Barro, I.F. (2015) Photocurrent and Photovoltage under Influence of the Solar Cell Thickness. ISJ Theoretical \& Applied Science, 7, 1-6. http://dx.doi.org/10.15863/TAS.2015.07.27.1

[4] Valkov, S. (1994) Electronique Analogique, Edition Castéilla, Collection A. CAPLIEZ.

[5] Levy, F. (1995) Traité des matériaux 18: Physique et technologie des semi-conducteurs. Presses Polytechniques et Universitaires Romandes.

[6] Dieme, N., Seibou, B., El Moujtaba, M.A.O., Gaye, I. and Sissoko, G. (2015) Thermal Behavior of a Parallel Vertical Junction Silicon Photocell in Static Regime by Study of the Series and Shunt Resistances under the Effect of Temperature. International Journal of Innovative Science, Engineering \& Technology (IJISET), 2, 433-437.

[7] Dieme, N., Zoungrana, M., Mbodji, S., Diallo, H.L., Ndiaye, M., Barro, F.I. and Sissoko, G. (2014) Influence of Temperature on the Electrical Parameters of a Vertical Parallel Junction Silicon Solar Cell under Polychromatic Illumination in Steady State. Research Journal of Applied Sciences, Engineering and Technology, 7, 2559-2562.

[8] Dieme, N. (2015) Study of the Electrons Density in the Base of the Parallel Vertical Junction Solar Cell under the Influence of the Temperature. American Journal of Optics and Photonics, 3, $13-16$.

http://dx.doi.org/10.11648/j.ajop.20150301.13

[9] Diallo, L.H., Dieng, B., Ly, I., Dione, M.M., Wereme, A., Ndiaye, M. and Sissoko, G. (2012) Determination of the Recombination and Electrical Parameters of a Vertical Multijunction Silicon Solar Cell. Research Journal of Applied 
Sciences, Engineering and Technology, 4, 2626-2631.

[10] Sze, S.M. and Ng, K.K. (2007) Physics of Semiconductor Devices. 3rd Edition, John Wiley \& Sons, Hoboken.

[11] Schroder, D.K. (2006) Semiconductor Material and Device Characterization. 3rd Edition, John Wiley \& Sons, Inc., Hoboken.

[12] Barro, F.I., Gaye, S., Deme, M., Diallo, H.L., Samb, M.L., Samoura, A.M., Mbodji, S. and Sissoko, G. (2008) Influence of Grain Size and Grain Boundary Recombination Velocity on the Series and Shunt Resistances of a Polycrystalline Silicon Solar Cell. Proceedings of the 23rd European Photovoltaic Solar Energy Conference, 612-615. 